\title{
Intelección, concepto y semántica en la obra de Guillermo de Ockham
}

\author{
JEAN PAUl MARTÍNEZ ZEPEDA* \\ Pontificia Universidad Católica de Valparaíso (Chile) \\ jean.martinez.z@mail.pucv.cl
}

\begin{abstract}
Resumen
El presente estudio examina el carácter semántico del concepto en la obra de Guillermo de Ockham. Trabajo que comprende las siguientes etapas: primero, análisis del concepto a partir de las teorías de abstracción formal en Avicena y Tomás de Aquino. Segundo, comprensión de la primacía del conocimiento intuitivo sobre el conocimiento abstracto para la configuración del concepto. Tercero, análisis del carácter semántico del concepto en cuanto hábito mental, ipsamet intellectio, y signo que se predica de las cosas.
\end{abstract}

Palabras clave: Ockham, concepto, esencia, semántica y signo.

\section{Intellection, concept and semantics in the work of William of Ockham}

\section{Abstract}

This study examines the semantic nature of the concept in William of Ockham's work and considers the following aspects: first, the analysis of the concept based on Avicenna's and Thomas Aquinas' theory of formal abstraction; second, understanding that the intuitive knowledge has primacy over the abstract knowledge when shaping the concept and third, the analysis of the semantic nature of the concept as mental habit, ipsamet intellectio, and sign which predicates of things.

Key words: Ockham, concept, essence, semantics, sign.

* Doctor en Filosofía por la Pontificia Universidad Católica de Valparaíso. Docente de Filosofía Medieval y Moderna en la Facultad de Teología de la Pontificia Universidad Católica de Valparaíso. Artículos recientes del autor son: "Ockham y Wittgenstein. Acerca de los alcances y límites de la relación pensamiento-lenguaje" (2018) y "El conocimiento como sistema en el Tratado de la Naturaleza de David Hume" (2019). 
La importancia de la controversia en torno a la teoría del conocimiento y el lenguaje durante los siglos XIII y XIV se despliega en torno a la discusión sobre la naturaleza del concepto, su análisis determinará el rumbo filosófico de dos corrientes diversas: por un lado, una filosofía realista amparada en la necesaria primacía de un análisis metafísico sobre la naturaleza del conocimiento y, por otro, una filosofía nominalista orientada por una lectura lógica del mismo. En este contexto, la comprensión de estas posiciones tendrá en las figuras de Tomás de Aquino en el s.XIII y Guillermo de Ockham en el s.XIV dos referentes indiscutibles al momento de establecer la configuración de un conocimiento que, en el caso del nominalismo de Ockham, reconocerá el incipiente rol del análisis del lenguaje para explorar vías conducentes a la resolución de problemáticas gnoseológicas, posición que erigirá un giro hacia una aproximación semántica del conocimiento la cual determinará en forma decisiva las problemáticas filosóficas posteriores.

En atención a estas temáticas se establecen tres interrogantes que posibilitan y orientan el examen de la naturaleza del concepto de Ockham como sus eventuales implicancias: primero, ¿qué elementos intervienen en la abstracción del concepto en Avicena y Tomás de Aquino? Segundo, ¿qué razones sostienen la primacía del conocimiento intuitivo sobre el conocimiento abstracto de esencias para la configuración del concepto en Guillermo de Ockham? Tercero, ¿qué aspectos constituyen y permiten una lectura semántica del concepto en la obra de Guillermo de Ockham? Frente a estas cuestiones el presente estudio tiene por principal objetivo: reconocer y analizar la teoría del concepto en la obra de Guillermo de Ockham. Trabajo acompañado de los siguientes objetivos específicos: primero, analizar las facultades y etapas que posibilitan la abstracción del concepto en los pensamientos de Avicena y Tomás de Aquino. Segundo, reconocer y comprender el rol del conocimiento intuitivo de los singulares en la elaboración del concepto. Tercero, examinar los elementos que posibilitan un análisis semántico del concepto en la obra de Guillermo de Ockham. En consideración de estos objetivos el presente abordará las siguientes hipótesis:

Primero, para Avicena y Tomás de Aquino el conocimiento abstracto posibilita la comprensión formal del ente a partir del concepto-esencia. El conocimiento abstracto, elaborado a partir de la distinción de intelectos en agente y posible, considera un análisis teológico-filosófico en las reflexiones de Avicena y Tomás de Aquino manifestado desde el fundamental rol de la iluminación divina sobre el entendimiento humano para la abstracción del concepto. El rol de la teoría de la iluminación divina en el proceso 
de abstracción humana posee dos lecturas: por un lado, en el caso del filósofo árabe del s.XI Avicena, desde la figura de un Intelecto Agente único y separado que ilumina el intelecto humano para el proceso de ideogénesis elaborado en función de la división del entendimiento humano en cuatro intelectos, interpretación ejecutada desde una lectura neoplatónica de Aristóteles. Por otro lado, en el caso del filósofo escolástico del s.XIII Tomás de Aquino, por la acción de la iluminación divina sobre el entendimiento agente humano, en cuanto causa última que dispone a la razón natural a la intelección, es decir, dispone al entendimiento agente a la abstracción formal de esencias presentes en las especies sensibles para la configuración del concepto. Por consiguiente, en ambos autores el proceso intelectual articula un conocimiento objetivo del mundo que descansa en un conocimiento formal de los entes, esto es, mediante la adquisición del concepto en cuanto esencia de las cosas.

Segundo, para Guillermo de Ockham el conocimiento intuitivo permite la consideración semántica del concepto en cuanto hábito mental (IDsamet intellectio) y signo que se predica de las cosas. El conocimiento intuitivo establece la primacía del singular para el conocimiento evidente, en atención a la adquisición intelectual de conceptos en cuanto signos que denotan los diversos individuos contingentes que articulan lo que denominamos mundo. Bajo esta óptica, Ockham afirma el preponderante rol de la lógica al momento de examinar los términos que configuran el conocimiento objetivo y su distancia de un conocimiento abstracto formal de esencias, en particular, al momento de reconocer el conocimiento de los singulares en el campo de los límites de aquello que podemos afirmar sobre el mundo, en consecuencia, el conocimiento implica el fundamental análisis de la denotación de nuestros términos. En consideración de estas hipótesis el desarrollo del presente trabajo se divide en tres partes: primero, la abstracción del concepto en Avicena y Tomás de Aquino, Segundo, el conocimiento intuitivo en la configuración del concepto en Guillermo de Ockham. Tercero, el carácter semántico del concepto en la obra de Guillermo de Ockham.

\section{LA ABSTRACCIÓN DEL CONCEPTO EN AVICENA Y TOMÁS DE AQUINO}

Un primer referente en el estudio de Aristóteles es el célebre comentarista árabe Ibn Sina Avicena (980-1037) ${ }^{1}$. La erudición de este pensador

\footnotetext{
$1 \quad$ Nace en Afhana cerca de la localidad de Bujara, Uzbekistán. El pensador oriental realiza estudios de física, geometría, teología, filosofía, derecho y medicina, será ampliamente reconocido en este último campo en la Europa medieval por su célebre obra el Canon de la Medicina. Conocedor de la obra de Aristóteles, en particular de la Metafísica,
} 
se manifiesta en una reflexión filosófica que posibilitará en los escolásticos del s.XIII el desarrollo de ideas metafísicas fundamentales, tales como la distinción entre Ser Necesario (Dios) y ser posible (el mundo), o en el campo gnoseológico, en torno al proceso de abstracción y el carácter intencional del concepto ${ }^{2}$. Será, en este último campo, relevante su aporte para el desarrollo de aspectos de las teorías del conocimiento de los dominicos Alberto Magno y Tomás de Aquino.

En el ámbito de la gnoseología cabe considerar la explicación de Avicena en torno al proceso intelectual a partir de una lectura neoplatónica de Aristóteles, explicación elaborada en función de la Pseudo-Teología de Aristóteles, obra considerada del pensador griego pero que contenía las Enéadas V-VII de Plotino (Afnan, 1965: 195). En este contexto, los comentarios de Avicena desarrollan una interpretación neoplatónica que provocó no sólo una nueva lectura del estagirita, sino que, además, derivó en una forma distinta de concebir el rol del Intelecto Agente en el proceso de abstracción aristotélico. Ahora bien, es posible reconocer, además, en el pensamiento del filósofo árabe la concepción plotiniana de la emanación, a partir de la cual Avicena articula la relación entre Dios y el cosmos. Para el pensador oriental, de Dios emana el Inteligencia Agente separado y el mundo, siendo el Intelecto Agente separado el que ilumina al entendimiento humano para la acción intelectiva (Cruz, 1963: 54). Avicena, a partir de los conocimientos de la época, elabora un complejo análisis del proceso de intelección que tiene como protagonista al denominado Intelecto Agente separado ${ }^{3}$, lo cual plantea en los siguientes términos:

\footnotetext{
la cual comprenderá a partir de los comentarios realizados por su predecesor Al-Farabi (fallece, el 950) (Parain, 2004: 318). Entre las principales obras de Avicena se encuentran: La curación: Metafísica, La curación: Lógica, Libro de la Salvación, El Canon de la Medicina y Las Cuestiones Divinas (Avicena, 2006; 2009).

2 Véase sobre estos temas, Avicena, 2009: 33.100.120ss. Ahora bien, sobre el particular Manser nos dice: "Avicenna (...) elaboró ideas aristotélicas. Su demostración se basa en los conceptos ens neccessarium y contingens. Como quiera que Dios es el ser absolutamente necesario, que no tiene ninguna causa, ni puede, en virtud de su esencia, ser y no ser, sino que es interna y necesariamente, la existencia tiene que ser una 'condición para la constitución de la esencia del ente necesario', es decir, la esencia es la existencia misma. Por el contrario, todo ens contingens es, en virtud de su misma esencia, tal como puede ser y no ser, y, si es, tiene que tener una causa que le haya dado la existencia. Por lo tanto, la existencia le viene de fuera, como algo ajeno a la esencia" (Manser, 1947: 562-66).

3 Tal como se ha sostenido la lectura de Al-Farabi orientó la comprensión de Aristóteles para Avicena, este punto en particular, será abordado por el antecesor de Avicena el cual reconocerá la existencia de un Intelecto Agente separado el cual se encuentra en la Luna desde la cual ilumina el proceso intelectual para el conocimiento de las esencias (Cruz, 1963: 53-54).
} 
Como los inteligibles están en potencia en el alma y luego vienen a estar en acto, hace falta que haya una entidad inteligente que les haga pasar de la potencia al acto. No hay duda de que esa entidad es uno de los intelectos de los que hemos hablado en Metafísica -en particular aquél que está más próximo a este bajo mundo y al que se llama Intelecto Agente-, que es el que actúa sobre nuestros intelectos para hacerlos pasar de la potencia a acto. Pero mientras que no existen previamente las sensaciones y las imaginaciones, nuestro intelecto no puede pasar a acto. Y cuando las sensaciones y las imaginaciones vienen a la existencia, las formas (sensibles) se juntan con los accidentes (individuales y materiales) que le son ajenos (a su esencia) y entonces se cubren con un velo como las cosas que se hallan en la oscuridad. Pero enseguida la iluminación del Intelecto Agente cae sobre las imaginaciones de la misma manera que el sol cae sobre las formas de las cosas que se hallan en la oscuridad. A continuación, partiendo de estas imaginaciones, las formas abstractas se presentan al intelecto, de la misma manera que a causa de la luz las formas visibles se presentan a la vista: como estas formas son abstractas, son universales. (Avicena, 2009: 181)

Podemos reconocer, por tanto, que el proceso intelectual se erige en virtud de las facultades sensibles que posibilitan la presentación del fantasma (imagen) a las facultades intelectuales humanas, las cuales actualizan las formas presentes desde los fantasmas mediante un proceso de abstracción formal que sólo es posible por la iluminación del Intelecto Agente separado.

El desarrollo del proceso de intelección implica, para Avicena, la división del intelecto humano en cuatro intelectos ${ }^{4}$ los cuales permiten la elaboración del concepto en un proceso sucesivo en cuatro etapas: primero, el intelecto material, dispuesto al conocimiento de los inteligibles en potencia, tal como la materia prima lo está a las formas. Segundo, el intelecto en hábito que posee los principios intelectuales que permiten la abstracción, por ejemplo, el principio de contradicción. Tercero, intelecto en acto el cual abstrae la forma-esencia actualizada ${ }^{5}$. Cuarto, el intelecto adquirido el cual posee

4 La división de los cuatro intelectos tiene como referente la división del intelecto de Alejandro de Afrodisia para quien existe el intelecto material, como disposición y en acto (Parain, 2004: 88). Sin embargo, es el pensador Al-Farabi donde aparece la distinción de cuatro intelectos: Intelecto en potencia, intelecto en acto, intelecto Agente e Intelecto Adquirido (Cruz, 1963: 56).

5 Acerca de las eventuales razones de la distinción entre los intelectos agente y posible en Afrodisia, Parain afirma: "El problema es a grandes rasgos el siguiente: ¿qué es acto y qué es potencia en el intelecto? ¿Es pura receptividad o pensamiento activo, capaz de distinguir por sus operaciones las formas inteligibles de la materia sensible? Según la teoría peripatética del conocimiento, los dos aspectos existen con seguridad: pero ¿cómo se pasa de uno a otro? Los estoicos habían respondido: mediante el desarrollo natural de 
el concepto-esencia y la actividad intelectual consciente ${ }^{6}$. El proceso de abstracción elaborado por el intelecto humano es posibilitado en cada una de sus fases por la iluminación del Intelecto Agente separado, manifestado en un proceso semejante a la iluminación del sol que nos permite reconocer las formas y colores de los cuerpos. Por consiguiente, la iluminación del Intelecto Agente separado afecta los entendimientos humanos en todos sus procesos intelectuales, disponiendo a la acción intelectiva a los cuatro intelectos. Cabe señalar que la perfección del conocimiento permitirá mediante la adquisición de esencias el mayor desarrollo del intelecto adquirido que dispondrá, en el caso de los Sabios, hacia el conocimiento interior y el encuentro consigo mismos mediante la unidad con los inteligibles (Avicena, 2009: 54).

Un segundo referente del análisis del proceso de abstracción de Aristóteles es el dominico Tomás de Aquino (1225-1275). La lectura aristotélica que realiza Tomás de Aquino conlleva los comentarios del pensador árabe Avicena lo cual incidirá en la concepción de la metafísica elaborada por el dominico en este período.

En consideración de estos elementos es necesario comprender que la llamada escolástica se erige en diálogo entre teología y filosofía ${ }^{7}$ en el siglo XIII. La nueva scientia medieval mantendrá la razón como una aliada de la fe, en particular, al momento de señalar las huellas del Creador en su obra

las nociones comunes. Por eso era admitir que estas nociones eran inmanentes a lo sensible y negar con ello la trascendencia del intelecto. Por ello, Alejandro se refiere a la solución, que se inspira en una distinción entre el espíritu agente y el espíritu receptivo, pasivo, en potencia" (Parain, 2004: 87-88). Véase, además, sobre la relación entre Alejandro y Avicena (Afnan, 1965: 185).

$6 \quad$ En palabras del pensador árabe: “Es preciso saber lo siguiente: el primer grado de conocimiento teórico, para el alma humana, es la recepción de los inteligibles (...) Para ese primer grado, el alma es una tabla rasa y ninguna forma inteligible se halla en ella, pero es apta para recibir esos inteligibles. A este primer grado se le llama inteligencia material o intelecto en potencia. A continuación (hay que saber que) hay dos clases de inteligibles que (el alma) recibe: 1) Las verdades primeras que por su esencia recibe, que son las que hemos tratado en la lógica 2) Las opiniones que el alma recibe habitualmente; la utilidad de las opiniones se da sobre todo en la vida práctica; y cuando es así se llama intelecto en hábito, es decir, intelecto práctico, que le hace capaz de conocer cosas. El tercer grado consiste en que el alma recibe los inteligibles; se le llama intelecto en acto. A la forma de estos inteligibles que se realiza en el alma se le llama intelecto adquirido, cuando reside en el alma" (Avicena, 2009: 175).

7 En palabras de Gilson la obra de Tomás de Aquino tiene como horizonte el encuentro con la trascendencia, en ese sentido: “(...) sus obras sistemáticas son sumas de Teología y, que por consiguiente, la filosofía que exponen nos es ofrecida según el orden teológico. (...) Por eso mismo, la teología natural, así comprendida, nos invita a contemplar el universo tal como es, con Dios como principio y como fin" (Gilson, 1976: 492). 
y así acceder a reconstruir paso a paso los elementos del mundo que le permitan descubrir los principios inmutables que den razón del encuentro con lo divino (Torrell, 2002: 132-133). En este contexto, la metafísica de Aristóteles será una fundamental herramienta del pensador escolástico al momento de develar los principios del orden real (Gilson, 1976: 498-502) que permitirá el desarrollo de una Teología natural (Elders, 2009: 63-64). Por consiguiente, el verdadero conocimiento será fruto de un arduo proceso intelectual en el cual tendrán un rol central la búsqueda de definiciones que logren captar certezas invariables, certezas que develen no sólo el orden del cosmos sino también permitan el acceso intelectual al Dios creador del universo.

Bajo este aspecto, autores como Alberto Magno y Tomás de Aquino, abordan el estudio de ciertos aspectos del pensamiento de Avicena, en particular, respecto a una lectura teológica-filosófica que explique metafísicamente cuestiones tales como la distinción entre un Dios creador y el $\operatorname{cosmos}^{8}$ y la naturaleza del conocimiento (Afnan, 1965: 359-360). La relación entre ambas posiciones cobrará forma en las teorías del conocimiento planteadas por la figura de Alberto Magno (1206-1280), dominico Alemán Maestro de Tomás de Aquino, pensador que acogerá algunas tesis de Avicena para realizar su síntesis teológica cristiana a partir de nociones filosóficas (Afnan, 1965: 356), entre algunas de ellas se encuentran: la división entre Ser necesario y ser posible, la división del universal en ante rem (en la mente divina), in rem (en la cosa) y post-rem (en el intelecto) y la teoría de la abstracción formal ${ }^{9}$.

Ahora bien, respecto al proceso de abstracción Santo Tomás señala desde su Proemio al Comentarios al Peri Hermeneias que, de acuerdo a lo manifestado por Aristóteles en el libro III del De Anima, la acción del entendimiento comprende: por un lado, la inteligencia de lo indivisible, esto

8 Sin embargo, existen diferencias importantes entre las posiciones de Avicena y la perspectiva propia de Tomás de Aquino respecto a la naturaleza del Ser necesario y el modo de existencia (Gilson, 2005: 116-117).

$9 \quad$ Sobre el proceso de abstracción Alberto Magno afirma: “(Por la abstracción el entendimiento) el que aprehende las quididades de las cosas despojadas de todas las condiciones de la materia y no las recibe con las intenciones sensibles, sino más bien como simples y separadas de ellas. Y esa aprehensión es de sólo el entendimiento, como es el concepto del hombre en cuanto que conviene a todo hombre, o el concepto de la sustancia, y, para decirlo de una manera general, el concepto de la quididad universal de toda cosa, en cuanto que es su quididad y no en cuanto que conviene a éste o aquél. Pues lo que conviene a uno y no a otro, es algo propio y singular, y pertenece a las condiciones materiales e individuales. En cambio, todo lo que es común y se halla tanto en uno como en otro y de la misma manera, es sin duda universal, que sólo es percibido por el entendimiento" (Fernández, 1980: 181). Véase, además, Elders (2009: 53); Manser (1947: 580-581). 
es, aquella por la cual es capaz de abstraer las formas esenciales de las cosas y, por otro, el razonar, manifiesto en la composición y división de los términos ${ }^{10}$. Según Santo Tomás: "Como dice el filósofo en el libro III del Acerca del Alma, la operación del intelecto es doble: una, en efecto, es llamada inteligencia de lo indivisible, por la cual el intelecto aprehende la esencia de cada cosa en sí misma, otra es, la operación del intelecto que compone y divide" (Aquino, 1990: 3). Ahora bien, en virtud de estas distinciones examinaremos a continuación la naturaleza del concepto en dos partes, primero, respecto a la actividad de la aprehensión y, segundo, en torno al razonamiento.

Primero, acerca de la aprehensión Tomás de Aquino continúa la recepción de Aristóteles en el pensamiento cristiano. Santo Tomás, desde las reflexiones de Avicena y Alberto Magno, reconocerá en la teoría de la iluminación divina la causa última que dispone la razón natural hacia el proceso de abstracción lo cual describe del siguiente modo:

Algunos sostuvieron que este entendimiento sustancialmente separado es el entendimiento agente, que, esclareciendo las imágenes, las hace inteligibles en acto. Pero, aún suponiendo que dicho entendimiento agente separado exista, siempre será necesario admitir en la misma alma humana una facultad participada de aquel entendimiento superior por la que haga a las cosas inteligibles en acto (...) cuando observamos que las formas universales las abstraemos de sus condiciones particulares, $\mathrm{y}$ en esto consiste poner en acto lo inteligible. A un ser nunca le corresponde una acción si no es por algún principio formalmente presente en él, tal como dijimos anteriormente al hablar del entendimiento posible. Por lo tanto, es necesario que la energía que es principio de esta acción sea algo propio del alma. Así como Aristóteles compara el entendimiento a la luz, que es algo que se recibe en el aire. Platón como dice Temistio en el III De Anima, comparó con el sol el entendimiento separado, que infunde su luz en nuestra alma. Según los documentos de nuestra fe, el entendimiento separado es el mismo Dios, creador del alma, y el único en el que está la bienaventuranza, como se demostrará más adelante (q.90 a.3; $1-2$ q.3 a.7) Por eso, de El mismo participa el alma humana su luz intelectual, siguiendo aquello del Sal. 4,7: Señor, marcada está en nosotros la luz de tu rostro. (Aquino, 2009: 726)

10 Además, en palabras de Santo Tomás: "Donde es menester que una de las dos operaciones del intelecto es la inteligencia de lo indivisible, a saber, en cuanto el intelecto entiende en absoluto la quididad, o sea, la esencia por sí misma, de cada cosa, por ejemplo, qué es hombre o qué es blanco o qué es algo por el estilo. Pero la otra operación del intelecto es según que por igual compone y divide los conceptos simples" (Aquino, 1990: 16). 
Es posible reconocer que, para Tomás de Aquino, el proceso de abstracción se articula en función de los sensibles propios de los cinco sentidos reunidos por la imaginación para la configuración del fantasma. De esta manera, la acción del entendimiento agente en el entendimiento humano es ejercida sobre el fantasma abstrayendo la forma ${ }^{11}$ de la materia ${ }^{12}$ la cual, finalmente, es recibida en cuanto especie inteligible en el entendimiento posible. En este contexto, el autor sostiene:

Así, pues, si el intelecto posible tiene que ser movido por lo inteligible, es necesario que de esta manera, lo inteligible sea producido por el intelecto $(. .$.$) es necesario admitir, además del intelecto posible, un inte-$ lecto agente que haga en acto los inteligibles que mueven al intelecto posible. Mas los hace por abstracción de la materia y de las condiciones materiales (...). (Aquino, 1999: 48)

Desde el proceso de abstracción formal se concibe que el carácter intencional del concepto descansa en su naturaleza esencial común ${ }^{13}$ mediante la cual es posible distinguir entre un "ser intencional", en el alma, de otro denominado "ser natural", en cuanto objeto exterior (Aquino, 2009: 631).Por otro lado, cabe señalar que la posición de Tomás de Aquino dista de la existencia de un Intelecto Agente separado, según lo planteado por Avicena, en cuanto, para el dominico, el intelecto agente que ejecuta la abstracción es propio del hombre. En palabras de Santo Tomás:

11 Ahora bien, Santo Tomás en su Proemio al Comentarios al Peri Hermeneias aclara que, según Aristóteles en el libro III del De Anima la acción del entendimiento es triple: primero, la llamada inteligencia de lo indivisible por la cual es capaz de abstraer las esencias de las cosas. Segundo, el intelecto que compone y divide. Tercero, la de razonar, por la cual se va de lo conocido a lo desconocido (Aquino, 1990: 3-4).

12 Además, sobre el particular véase (Aquino, 1999: 51).

13 Sobre el particular Spruit afirma: "Thomas is careful, however, to point out that the intelligible representational of mind's object is not merely replica or sensible representational devices. The crucial difference between phantasm and intelligible species -as we shall see more in detail below-boils down to the idea that the latter is capable of representing a sensible essence as universal with the help of the agent intellect. Now, the species contains as 'similitudo' the thing itself, that is, the species is an intentional representation of the essence in its fundamental features" (1994: 160). Y más adelante: "It would be incorrect to say that the species is an abstract entity because of its universality, since the latter feature merely indicates that the species expresses an essence common to a plurality of individuals" (1994: 169). En el pasaje anterior Spruit nos remite al siguiente comentario de Tomás de Aquino: "Según Avicena, la especie inteligible puede ser considerada de dos modos: o según el ser que tiene en el intelecto, y así tiene un ser singular; o según que es semejanza de tal cosa inteligible, en cuanto que lleva al conocimiento de ella; y por esta parte tiene universalidad, ya que no es la semejanza de la cosa en tanto es ésta, sino según la naturaleza en la que conviene con las otras de su especie" (Aquino, 2005: 513) 
Esta es la opinión de Avicena, según la cual el alma humana no puede pasar al acto su propia operación, que es el conocimiento de la verdad, si no es iluminada por una luz exterior, es decir, por aquella sustancia separada que llaman intelecto agente (...) Sin embargo, las palabras del filósofo en el De Anima parecen dar a entender que el intelecto agente es una potencia del alma. (Aquino, 1986: 74)

De este modo, la lectura de Santo Tomás reconoce que las potencias activas y pasivas en el alma bastan para el conocimiento de la verdad según lo sostenido por Avicena (Elders, 2009: 195). Sin embargo, en cuanto "causa última" de la luz por la cual el ser humano intelige, es necesario sostener que la mente humana es iluminada por Dios. Según el autor: “(...) la mente humana es iluminada por Dios (...). En efecto, el obrar constante de Dios en la mente consiste en causar en ella la luz natural y dirigirla. De este modo, y no de otro, la mente humana no obra sin la operación de la causa primera" (Aquino, 1986: 77). Sobre esta misma temática, Tomás de Aquino en sus Cuestiones Disputadas sobre el alma reconoce que:

(...) debe decirse que el intelecto agente no basta por sí mismo para la reducir en acto al intelecto posible, dado que no existen en él determinadas especies para todas las cosas, como se ha dicho. Y, por ello, para la perfección última del agente se requiere que se una de alguna manera a aquél agente en quien se hallan las razones de todas las cosas, es decir, a Dios" (Aquino, 1999: 62).

Finalmente, en este contexto, se establece que el concepto en cuanto esencia universal de las $\operatorname{cosas}^{14}$ es ya una "intención". De este modo, Tomás de Aquino es claro en sostener la diferencia entre el objeto en la mente

$14 \quad$ En palabras de Leo Elders: "Tomás comienza su discusión de la esencia notando que con esta palabra significamos algo que es común a todas las cosas existentes (naturae) de una u otra clase. A causa de su esencia las cosas se clasifican en géneros y especies. Así la esencia significa la quidditas (lo que son) de las cosas. Un sinónimo de esencia es naturaleza. Pero la naturaleza significa la esencia de las cosas en cuanto están ordenadas a su propia actividad (...) Tomás se refiere a Avicena, cuando explica cómo obtenemos el concepto de esencia. Al considerar una cosa notamos que tiene un contenido. El término cosa res significa la quidditas o la esencia de las cosa, luego, cuando el ente es considerado en un modo negativo se llega al concepto de ente indiviso, es decir uno. El concepto res sigue al concepto de ente y se alcanza cuando se considera el contenido -que es el contenido de uno u otro de los predicamentos, como la sustancia, la cantidad, la cualidad, etcétera- Los accidentes tienen una esencia. Nuestro concepto de esencia es universal, pero la esencia es realizada siempre individualmente en las cosas existentes" (Elders, 2009: 195, 245). Además, P. Manser en su Esencia del tomismo sostiene: "Cuán rigurosa (...) concibió Tomás el problema de los universales, se deduce claramente del hecho de que, en el concepto del universal, todo lo concentro sobre la esencia, la 'natura' 
y el objeto real exterior a partir de la distinción conceptual de "ser intencional" y "ser natural".

Segundo, respecto al rol del concepto en el razonamiento. Conviene precisar que, desde el punto de vista lógico, el análisis del concepto conlleva la clasificación de los términos, en particular, al momento de reconocer su rol en la formulación del juicio, esto es, en la composición y división $^{15}$ expresada en la correspondencia entre el sujeto y el predicado en el enunciado. Tomás de Aquino analiza la clasificación de los términos en sus Comentarios al Peri Hermeneias a partir de la posición de Boecio, quién los divide en conceptos, voces y palabras, donde los conceptos serán comprendidos como determinadas pasiones del alma, en palabras del pensador dominico: "De donde la concepción del intelecto puede llamarse pasión (...) porque extendido el nombre pasión a toda recepción, también el entender del intelecto posible es cierto padecer, como se dice en el libro III Acerca del alma" (Aquino, 1990: 11). Para el dominico, por tanto, el carácter pasivo del entendimiento posible posibilita la recepción del concepto, el cual se erige como una cierta semejanza de las cosas. Por otro lado, es necesario reconocer que las voces y palabras son signos convencionales subordinados a los conceptos, lo cual sostiene al afirmar: “(...) dice (Aristóteles) que las pasiones del alma son semejanzas de las cosas (...) Así las letras son signos de las voces, y las voces de las pasiones, en tanto que no se atiende allí razón de semejanza, sino sólo razón de institución (...)" (Aquino, 1990: 13). De acuerdo a lo planteado, el significado de voces y palabras descansa en las concepciones del intelecto, las cuales son abstracciones de los singulares, en palabras del autor:

Pero no puede ser que signifiquen inmediatamente a las cosas, como se hace evidente por el modo de significar mismo, pues este nombre Hombre, significa la naturaleza humana en una abstracción de los singulares. De donde no puede ser que signifique inmediatamente un hombre singular, de donde los platónicos establecieron que significara a la idea de hombre separada. Pero, ya que esto no subsiste realmente en cuanto a la abstracción, de acuerdo a la doctrina de Aristóteles, sino está sólo en el intelecto, por ello le fue necesario a Aristóteles decir que las voces significan inmediatamente las concepciones del intelecto, y mediante ellas, las cosas. (Aquino, 1990: 11)

que el universal presenta: la única y misma esencia, tal como existe en sí, en el entendimiento y en la cosa singular" (Manser, 1947: 263). Véase también sobre el particular: Gilson (2005: 262-263); Forment (2009: 226-227); Brennan (1960: 227). Finalmente, acerca de la definición de las esencias, véase, Aristóteles (2007: 217).

15 “(...) por ello el intelecto no conoce la verdad sino al componer o al dividir mediante su juicio" (Aquino, 1990: 19) 
Santo Tomás, por consiguiente, sostiene la universalidad de los términos en virtud de las abstracciones de los singulares (Spade, 2007: 81.162), posición que dista de la significación en virtud de su correspondencia con ideas separadas. Sin embargo, en cuanto a la naturaleza del cosmos la realidad se articula en función de las esencias creadas por Dios a modo de un artífice que construye su obra:

Y ya que también todo lo natural se compara con el intelecto divino, tal como lo artificial con el arte, se sigue que cualquier cosa se dice que es verdadera en cuanto que tiene la forma propia, según la cual imita el arte divino (...) De donde el Filósofo, en el libro I de la Física, denomina a la forma algo divino. (Aquino, 1990: 19)

En consecuencia, para Tomás de Aquino el conocimiento evidente consiste en el conocimiento de las esencias que el mismo arquitecto del cosmos creo para construir su obra ${ }^{16}$. El conocimiento de esencias será expresado a partir de definiciones las cuales constituirán los logros intelectuales de la época y el conocimiento objetivo del mundo.

\section{EL CONOCIMIENTO INTUITIVO EN LA CONFIGURACIÓN DEL CONCEPTO DE GUILLERMO DE OCKHAM}

La teoría conceptual del nominalista Guillermo de Ockham comprende su lectura del conocimiento asociada a la primacía del conocimiento intuitivo sobre el conocimiento abstracto, posición articulada en la obra de Ockham ${ }^{17}$, principalmente, desde los Comentarios a las Sentencias y el Comentarios al Peri Hermeneias.

El análisis de la naturaleza del concepto en el pensamiento de Ockham implica el desafío de describir la lectura del proceso intelectual, la que tiene como antecedente directo la gnoseología realista de Tomás de Aquino en la cual destaca la visión del mundo a partir del proceso de abstracción formal. En consideración de su predecesor, el nominalismo de Guillermo de Ockham erige la primacía del conocimiento intuitivo del singular sobre el conocimiento abstracto formal de esencias, perspectiva que dispone a un

16 Por otro lado, en el caso de Ockham, su lectura teológica sobre la creación plantea su examen a partir de la Omnipotencia divina, esto es, Dios no se encuentra atado a nada en su creación. Sobre la absoluta Omnipotencia divina y sus posibilidades, véase Ockham (1967: 49). Además, De Andrés (1969: 67-68).

17 Véase, Suma de la Lógica (Ockham, 1974), Comentarios al Peri Hermeneias de Aristóteles (Ockham, 1978) y Comentarios a las Sentencias, Ordinatio (Ockham, 1967; 1970). Se utiliza la edición en español de Fernández (1980). 
examen semántico del conocimiento a través del detenido análisis del lenguaje como modo de acceder a una comprensión de la realidad. Bajo este contexto, el presente apartado tiene como principal propósito ejecutar un análisis de la primacía del conocimiento intuitivo de los singulares sobre el conocimiento abstracto en la obra del franciscano inglés.

Ockham asume la concepción intelectual de la singularidad desde la operación unitaria del entendimiento humano sin establecer ulteriores distinciones entre intelectos agente y posible (De Andrés, 1969: 106-111). El pensador inglés, se distancia de la comprensión de determinadas especies inteligibles en cuanto esencias de objetos exteriores (Panaccio, 2004: 2829), posición planteada por el pensamiento de Tomás de Aquino, la cual es preciso reconocer en los siguientes términos:

Nuestro entendimiento no puede conocer primaria y directamente lo singular de las cosas materiales. El porqué de esto radica en que el principio de singularización en las cosas materiales es la materia individual y nuestro entendimiento tal como lo dijimos, conoce abstrayendo la especie inteligible de la materia individual. Lo abstraído de la materia individual es universal. Por eso, nuestro entendimiento no conoce más que lo universal. (Aquino, 2009: 786.)

En consecuencia, el dominico concibe la abstracción de universales a partir de los cuales el entendimiento humano ejecuta su operación formal. En este contexto, la universalidad de los términos se funda en el conocimiento formal de esencias, que orientan la objetividad y certeza del conocimiento (Aquino, 1990: 3), según lo ya manifestado en el apartado anterior. En virtud de esta posición, el franciscano inglés Guillermo de Ockham erige en sus Comentarios a las Sentencias la primacía del conocimiento intuitivo sobre el abstracto (De Andrés, 1969: 70). En este sentido, el conocimiento se articula a partir de los singulares lo cual se manifiesta en la elaboración de un conocimiento objetivo que no precisa de la mediación de esencias presentes en las cosas, en palabras del franciscano: "Si una realidad existente fuera del alma es esta tierra o aquella, luego es verdaderamente singular, y, por consiguiente, es entendido singularmente" (Ockham, 1970, 488 [Fernández, 1980: 1052]) ${ }^{18}$.

18 Véase, a continuación, el texto de Tomás de Aquino al cual aludiría Ockham (Fernández, 1980: 1052). En palabras del dominico: “(...) la humanidad conocida no existe más que en este o aquel hombre. El que sea percibida sin las condiciones individuantes, en lo cual consiste su abstracción y de lo que se sigue su universalidad conceptual, le viene del hecho de ser percibida por el entendimiento, en el que se encuentra la representación de su naturaleza específica y no la de sus principales individuales" (Aquino, 2009: 777). 
Ahora bien, dado que el conocimiento del singular es lo primero al entendimiento, la misma especie sensible en función de su propia objetividad podrá representar por sí misma a otros singulares, razón por la cual todo conocimiento cierto sólo puede ser construido a partir del conocimiento intuitivo (Panaccio, 2004: 6-7). Por lo tanto, el conocimiento intuitivo corresponderá al conocimiento evidente de los singulares ${ }^{19}$. Según Ockham:

El conocimiento intuitivo de una cosa es un conocimiento de tal índole, que en virtud de él se puede saber si la cosa existe o no, de suerte que, si existe, al punto juzga el entendimiento que existe y conoce evidentemente que existe, a no ser que sea impedido por la imperfección de tal conocimiento. (Ockham, 1967: 31 [Fernández, 1980: 1013])

Además, en palabras del pensador inglés: “(...) la especie sensible misma es semejanza de todos los singulares, y, por consiguiente, podrá representar al universal lo mismo que lo hace la especie inteligible" (Ockham, 1970: 489; [Fernández, 1980: 1052]) ${ }^{20}$. Sin embargo, frente a la objeción de reconocer la capacidad de las especies sensibles para representar otros singulares, el autor expresa:

Si se replica que la especie sensible es precisamente semejanza de un singular, y no de otro, y no así la especie inteligible, respondo: siempre que se dan cosas muy semejantes entre sí, lo que se asemeja a una de ellas, se asimila igualmente a otra; pero algunas blancuras pueden ser o son muy semejantes; luego la especie sensible se asemeja igualmente a una que a otra, y así será semejanza tanto de la una como de la otra (Ockham, 1970: 489 [Fernández, 1980: 1053])

Por consiguiente, la misma especie sensible podrá por semejanza representar $^{21}$ a otros singulares, razón por la cual el conocimiento singular no es posterior al conocimiento abstracto, lo cual sostiene al afirmar:

19 En este sentido el conocimiento intuitivo se distingue del abstractivo, en palabras de Ockham: "Ideo dico quod notitia intuitiva et abstractiva se ipsis differunt et non penes obiecta nec penes causas suas quascumque, quamvis naturaliter notitia intuitiva non possit esse sine exsistentia rei, quae est vere causa efficiens notitiae intuitivae mediata vel immediata, sicut alias dicetur. Notitia autem abstractiva potest esse naturaliter ipsa re nota simpliciter destructa" (Ockham 1967: 38).

$20 \quad$ El texto de Tomás de Aquino al que aludiría Ockham es el siguiente: "El universal puede ser considerado (...) Uno, en cuanto que la naturaleza del universal implica la intención de universalidad. Como la intención de universalidad, esto es, que una y la misma cosa se refiera a muchas, proviene de la abstracción del entendimiento, es necesario que lo universal, bajo este aspecto, sea posterior". (Aquino, 2009: 779)

21 Cabe señalar que en una fase temprana de su pensamiento, esto es, a partir de los Comentarios a las sentencias (1317) Ockham si bien reconoce el concepto como un signo 
En cuanto a lo que dice que el entendimiento conoce propiamente al singular por cierta reflexión, arguyo: o tiene un acto distinto por el cual entiende el universal o no (...) Si lo tiene, pregunto por quién es causado: o por el fantasma mismo, o por algo en la parte sensitiva, o por la especie inteligible, o por el acto por el cual se entiende el universal. Si es de los tres primeros modos, y es verdad que, pues las causas suficientes, se puede poner el efecto, luego, aun sin contar con la intención del universal, podría ponerse el conocimiento sensitivo, y así no iría contra el entendimiento el que el conocimiento singular fuese el primero. (Ockham 1970: 490 [Fernández, 1980: 1053])

Podemos apreciar, por tanto, que en los Comentarios a las Sentencias la posición de Ockham recoge la cuestión del conocimiento de los singulares como un aspecto central que orienta toda su teoría del concepto, con total distinción al conocimiento abstracto formal ${ }^{22}$. De esta manera, el análisis conceptual de Ockham se erige de manera distinta a lo planteado por Tomás de Aquino donde, para este último, el conocimiento en forma necesaria asciende de los singulares a esencias universales que permiten la génesis de un conocimiento perfecto que surge de la reflexión, razón por la cual se reconoce el conocimiento abstracto en cuanto más perfecto que el conocimiento sensible. Por otro lado, en el caso de Ockham, el conocimiento sensible ya es evidente y no precisa de una ulterior multiplicación de esencias ${ }^{23}$ para ser comprendido, de este modo, toda la arquitectura de esencias que justificaba el conocimiento objetivo no es necesaria.

Cabe añadir que la singularidad de las cosas obedece a la unidad que las constituye, razón por la cual ellas son por sí mismas y no por algo añadido. En palabras del franciscano: "Toda cosa singular es por sí misma singular. Y lo pruebo, así: la singularidad compete inmediatamente a aquello de lo cual es (singularidad); luego no puede competerle por alguna otra cosa; luego, si algo es singular, lo es por sí mismo" (Ockham, 1970: 196 [Fernández, 1980: 1033]). Además, al sostener: "De todo esto se sigue que toda cosa existente fuera del alma es por sí misma singular, de suerte que

este mantiene una carga representativa. Sin embargo, en un fase de posterior de su pensamiento tal como es expuesto en la Suma de la Lógica y La Exposición a los ocho libros de la Física (1324) el autor inglés considera el concepto desde una lectura estrictamente semántica en cuanto "hábito mental".

22 Sobre el particular, Ockham sostiene: "Ahora bien, el universal es más imperfecto y posterior al singular, luego el entendimiento no conoce el objeto de los sentidos de modo más eminente”. (Ockham, 1970: 495 [Fernández, 1980: 1056])

23 Este aspecto alude al célebre principio de economía, también denominado navaja de Ockham el cual establece que "no se debe multiplicar los entes sin necesidad" (Ockham, 1974: 185). 
ella misma, sin ningún aditamento, es lo que recibe la denominación inmediatamente de la intención de singularidad" (Ockham, 1970: 197 [Fernández, 1980: 1034]). Por consiguiente, el conocimiento de los singulares y los hechos obedece a la atenta observación de las cosas y sus relaciones, razón por la cual no es posible sostener en la existencia de los singulares, formas absolutas que las determinen, ellas son por sí mismas individuales.

En consecuencia, podemos reconocer en el Venerabilis inceptor su distancia de una lectura que justifique la unidad de las cosas como algo añadido a las mismas y desde las cuales sea posible reconocer la objetividad del conocimiento. Desde esta perspectiva, una lectura metafísica del mundo no es sino un "conjunto de razonamientos abstractos" que establecen en ellos mismos la validez de la existencia de los singulares, razón por la cual estos singulares han de ser trascendidos a través de la contemplación y el discurso. De esta manera, la apreciación del conocimiento abstracto sobre la intuición de los singulares, para Ockham, sólo impone la multiplicación de entes abstractos que nos impide la comprensión de los singulares y sus relaciones. Por lo tanto, en consideración de lo expuesto, la validez de nuestra experiencia depende de la atenta observación de los hechos y no de la formulación de juicios invariables, posición que dará paso a un incipiente nominalismo en la concepción intelectual del s.XIV.

\section{EL CARÁCTER SEMÁNTICO DEL CONCEPTO EN OCKHAM}

Una vez reconocido el conocimiento intuitivo de los singulares es necesario examinar la configuración del carácter semántico del concepto en Ockham $^{24}$. Desde esta perspectiva, es relevante señalar que la posición del filósofo inglés obedece a un tránsito histórico de la filosofía manifiesto desde una lectura esencial del concepto, elaborada por las lecturas metafísicas del s.XIII, hacia una visión semántica del mismo, desplegada por el nominalismo del s.XIV.

Cabe señalar que el análisis del concepto como intención del alma es elaborado por los escolásticos del s.XIII, según lo mencionado previamente, lo cual tiene como antecedente las reflexiones de Avicena, Alberto Magno y Tomás de Aquino, quienes reconocen que los conceptos son "formas" o "intenciones" del alma en cuanto semejanzas de las cosas exteriores $^{25}$. Ockham, en este contexto, asume en una primera etapa de su

24 Se profundiza en torno al examen del concepto en cuanto signo en Ockham en (Martínez, 2018: 69ss). Por otro lado, un estudio de la naturaleza del concepto en Ockham en orden a la fundamentación de la scientia desde una visión nominalista será abordada en otro estudio.

25 Véase Alberti Magni (1890: 380) y Aquino (1990: 13-14). 
pensamiento la posición de sus predecesores en atención al análisis del concepto en cuanto "intención" o "cualidad" del alma ${ }^{26}$, no obstante, se distancia de las filosofías anteriores al desarrollar un análisis semántico del concepto en cuanto signum ${ }^{27}$. La posición del franciscano articula, por tanto, un denominado "sentido predicativo de la universalidad" de los términos (De Andrés, 1969: 70-72; Panaccio, 2004: 56) en el cual destaca el rol de los conceptos universales como signos que se predican de las cosas. Sobre el particular en la Suma de la Lógica afirma: “(...) la intención es algo existente en el alma, que es signo que significa naturalmente algo por lo cual la puede suponer o que puede ser parte de la proposición mental" (Ockham, 1974: 43 [Fernández, 1980: 1075]).

En este ámbito, cabe sostener que el inglés reconoce la existencia de dos clases de signos: por un lado, el signo denominado "intención primera" en cuanto aquel que supone por las cosas, en palabras del autor: “(...) ese signo se llama intención primera, como es la intención del alma que es predicable de muchos hombres” (Ockham, 1974: 43 [Fernández, 1980: 1075]), y de este modo: "En sentido estricto, se llama intención primera el nombre mental que es apto para suponer por su significado" (Ockham, 1974: 43 [Fernández, 1980: 1076]). Por otro lado, el signo que es "intención segunda" el cual corresponde a aquellas intenciones que son signos de las intenciones primeras, tal es el caso de "género" y "especie". Desde esta perspectiva, para el pensador franciscano, de una colección de hombres se predica una intención común, por ejemplo, al sostener: "animal es género" (Ockham, 1974: 43-44).

26 En palabras de Ockham: "Aliter posset poni quod ista qualitas esset aliquid aliud ab intellectione et posterious ipsa intellectione. Et tunc posset responderi ad motiva pro opinione illa de fictis in ese obiectivo sicut tactum est alibi, ubi magis expressi istam opinionem de intentione mentis animae seu conceptu, ponendo quod sit qualitas mentis" (1970: 291). Sobre el carácter intencional del concepto (Panaccio, 2004: 21-22).

27 De acuerdo a Panaccio, es fundamental reconocer en este punto que la teoría semántica del concepto en cuanto signo tendrá como antecedente a lógicos como William of Sherwood y Pedro Hispano. Ahora bien, sobre la función referencial del concepto en los lógicos modernos Panaccio afirma: "Even more importantly, the so-called terminist logic, which had been developed in the twelfth ant thirteenth centuries, is now being applied not only to spoken or written languages, as in Peter of Spain, William of Sherwood and the other early contributors to the logica modernorum, but also- and even primarily- to mental terms and proposition. Concepts are said to have a signification (significatio) or a connotation (connotatio) when they are considered in themselves, and a referential function (suppositio) when they occur within propositional contexts. It is one of Ockham's major innovations to have systematically transposed the terminist logic he had learned at school into a theory of discourse thought" (Panaccio, 2004: 8). Por otro lado, sobre el carácter del concepto en William Sherwood y Pedro Hispano, véase Spade (2007: 145). Véase, también, sobre estos autores, Gilson (1976: 514-515). 
Ockham identifica, además, dos rasgos que comprenden la universalidad del concepto lo cual sostiene en una etapa más avanzada de su pensamiento, esto es, desde la Suma de la lógica al señalar: primero, que el universal en cuanto signo se elabora a partir de los singulares y no desde la abstracción formal, tal como se ha analizado anteriormente. Segundo, que el universal en cuanto signo es un singular que "supone" en el alma por otros singulares, todo lo cual plantea al afirmar:

(...) la palabra 'singular' significa todo aquello que es uno y no muchos. En este sentido, los que sostienen que el universal es una cualidad de la mente predicable de muchos, si bien no tomado por sí, sino por esos muchos, deben decir que todo universal es verdadera y realmente singular; porque así como toda palabra, aunque sea común por convención, es verdadera y realmente singular y una numéricamente, porque es una y no muchas, así la intención del alma que significa muchas cosas fuera del alma es verdadera y realmente singular y numéricamente, porque es una y no muchas, aunque significa muchas cosas. (Ockham, 1974: 48 [Fernández, 1980: 1077])

Queda de manifiesto que, para Ockham, el universal, en cuanto a su significación, es reconocido como una cierta realidad singular (Ockham, 1974: 47). En virtud de lo señalado el carácter universal de los términos establece su comprensión estrictamente semántica en cuanto signo predicable de muchos y de ninguna manera en relación a sustancias inmateriales extramentales ${ }^{28}$, según el autor: 'Y tal universal no es más que una intención del alma, de suerte que ninguna sustancia existente fuera del alma ni ningún accidente es tal universal" (Ockham, 1974: 49 [Fernández, 1980: 1079]). Posición que el franciscano ratifica también desde la negación de la comprensión del concepto en cuanto esencia de las cosas (Spruit, 1994: 292), lo cual asevera del siguiente modo:

(...) todos los textos que parecen decir que los universales pertenecen a la esencia de las sustancias, o que son partes de las sustancias, deben

28 Un aspecto central para el conocimiento intuitivo de los singulares es la negación de sustancias inmateriales extra-mentales. En este contexto, Ockham afirma en el Proemio al Peri Hermeneias la imposibilidad de su existencia y que su aceptación implica la distancia del pensamiento de Aristóteles: "Una est quod res extra concepta sive intellecta est passio animae, illo quo ponunt aliqui quod praeter res singulares sunt res universales (...) Sed istam opinionem, quantum ad hoc quod ponit ese aliquas res extra praeter singulares exsistentes in eis, reputo omnino absurdam et destruentem totam philosophiam Aristotelis et omnem scientiam et omnem veritatem et rationem" (Ockham, 1978: 362). Por otro lado, cabe precisar que, en el caso de Tomás de Aquino, esta existencia de esencias se encuentra en la mente de Dios como se ha sostenido anteriormente. Véase, además, Panaccio (2004: 16). 
entenderse en el sentido de que los autores no pretenden decir otra cosa sino que tales universales declaran, expresan, explican, importan y consignifican las sustancias de las cosas. (Ockham, 1974: 60; [Fernández, 1980: 1084])

Para el pensador inglés, por consiguiente, el análisis del concepto es abordado desde su carácter estrictamente semántico ${ }^{29}$, donde la universalidad sólo comprende la extensión del concepto, esto es, un término que "supone" por conjuntos de singulares contingentes. La universalidad del término, por lo tanto, no se predica de una esencia formal inmutable (que determina la materia) ${ }^{31}$, aspecto desde el cual es posible afirmar que no hay algo añadido al singular.

A partir de estos aspectos el estudio semántico de Ockham exigirá una comprensión abierta y dinámica del concepto lo cual establecerá su descripción como un "hábito mental", es decir, los conceptos corresponden a la misma actividad del intelecto ${ }^{32}$ y en este sentido son la ipsamet intellectio (Ockham, 1970: 291; De Andrés, 1969: 165ss). Bajo esta nueva perspectiva, la adquisición de los conceptos mediante la reiteración de actos mentales en cuanto "hábitos" 33 se erige en virtud de la experiencia de singulares contingentes, aspecto que impone el carácter de nuestros conceptos los cuales pueden variar de significado en la medida que nuestra concepción

29 Spruit sintetiza esta cuestión del siguiente modo: " $A$ semantic notion that is crucial to Ockham's understanding the relationship between sensible things and concepts highlights the paradigmatic turn in his epistemology: concepts signify external objects, and do not represent them; no longer identified with the pictorial entities, concepts are signa. For attaining higher-level knowledge of reality, the human mind is structurally compelled to use linguistic signs, which in turn enable one to justify bow cognitive act relate to sensible objects without appeling to the mediation of similitudes arising from extra-linguistic reality" (1994: 297).

30 Acerca de la teoría de la suposición y sus distinciones, véase Ockham (1974: 195ss); De Andrés (1969: 248-250).

31 Sobre el particular véase la posición de Panaccio (2004: 28-29) acerca de las posiciones de Ockham y Tomás de Aquino.

32 Spade nos aclara esta difícil cuestión del siguiente modo: "Ockham originally favored a theory that regarded a concept as a kind of intentional object of a mental act of thinking or understanding, he later came to abandon that view in favor of a theory according to which a concept just is a mental act of thinking. The concept of cats, in other words, is just the act of thinking about cats -nothing more" (2007: 124).

33 Spade sintetiza esta cuestión en los siguientes términos: "What Ockham and fourteenthcentury nominalists in general do, in a sense, is to take the realist notion of a universal entity, and transfer in into the mind, where it becomes the notion of a universal concept. A universal concept is of course not universal at all in any metaphysical sense of the word. But, since concept are terms in mental language, a universal concept is universal in the other sense -it can be predicated of many" (2007: 147). 
del mundo cambia ${ }^{34}$. En este sentido, los conceptos, si bien son los mismos para todos los hombres en cuanto remiten por experiencia en forma necesaria a lo singulares y sus estrictas relaciones en la composición del mundo, se encuentran todos revestidos del cambio. En definitiva, el carácter significativo de nuestros conceptos se articula en función de un conocimiento intuitivo de singulares contingentes.

El franciscano inglés plantea la distancia de una lectura de los conceptos en tanto representaciones intencionales que plantean una visión del mundo configurado desde abstracciones formales (De Andrés, 1969: 4951). No obstante, si bien la posición de Santo Tomás constituye punto de vista distinto a los planteamientos sobre la naturaleza del concepto en Ockham, conforman un antecedente central en su análisis, en particular, respecto a la lectura del carácter significativo del concepto (Aquino, 1990: 19-20) o la cuestión de la intencionalidad analizadas por Ockham durante el período de redacción de sus In Peri Hermeneias (Ockham, 1978: 368-369) y que incidirán en sus análisis del concepto como signo e Ipsamet intellectio. En este sentido, apreciamos un proceso continuo en el examen de la naturaleza del concepto entre Tomás de Aquino y Ockham, que aun cuando difieran respecto al rol de las esencias (Spruit, 1994: 263), comparten la fundamental aproximación respecto al análisis del lenguaje y su labor en la construcción del conocimiento objetivo.

Ahora bien, la aproximación semántica al concepto en el autor inglés plantea un giro hacia el estricto rol del lenguaje y sus posibilidades en la construcción de nuestra visión del mundo. De este modo, la significación de los términos atiende a un contenido interior el cual es resultado de la función lingüística del concepto que se despliega en consideración de la contingencia del cosmos, posición que incide en una nueva vía de acceso al conocimiento objetivo ${ }^{35}$, sobretodo al negar el estatuto ontológico de las esencias para la comprensión de un mundo que es regido por un Dios Omnipotente a su voluntad (Gilson, 1976: 605-607; 2005: 119). En este sentido, podemos advertir una cuestión central: que la posición de Ockham acerca de la contingencia del cosmos y su comprensión tiene como precedente su misma postura teológica. Esta cuestión puede inducirnos a plantear hasta qué punto existe una manifiesta separación entre

34 Según Ockham: “(...) si conceptus ille mutaret significatum suum eo ipso ipsa vox, sine nova institutione, suum significatum permutaret" (1974: 8). Un ejemplo de ello es el concepto "árbol", el cual puede cambiar a partir de nuestra experiencia de las distintas especies, esto es, en la medida que varíen los distintos referentes a cosas singulares, por tanto, la posición de Ockham comprende una perspectiva distinta del conocimiento amparada en una lectura lógica de los términos basada en la predicación de los mismos.

35 Además, acerca de los signos naturales y convencionales, véase, Panaccio (2004: 51) y De Andrés (1969: 145). 
Teología y Filosofía en la obra de Ockham, idea muy difundida en los estudios de Filosofía medieval acerca de la incidencia del pensamiento del pensador inglés en un quiebre entre fe y razón a partir del s.XIV (Le Goff, 2008: 130-131). En este sentido, podríamos sostener que es precisamente la comprensión teológica, en virtud de una Omnipotencia y libertad divina desprovistas de todo determinismo natural de esencias, un aspecto central que conduce a reconocer conceptualmente los singulares y sus relaciones bajo el conocimiento intuitivo de un cosmos dinámico, paso crucial para volcar el conocimiento objetivo a partir de una perspectiva lógica que tenga como referente la descripción de hechos, posición a analizar en otros estudios. En definitiva, en la lectura del concepto de Ockham, la relación entre pensamiento y lenguaje se vuelve más estrecha lo cual nos permite examinar el concepto, por un lado, ajeno a una posición esencialista y, por otro, más próximo al análisis del lenguaje.

En consecuencia, a finales de la obra de Ockham el concepto es ya un signo, la transformación semántica del concepto hacia su lectura lógica ha quedado instituida. En este sentido, el pensador franciscano será enfático en afirmar que la cuestión del contenido mental no es asunto del lógico ${ }^{36}$. El análisis de los comentaristas anteriores al Peri Hermeneias recogía de algún modo la cuestión de la abstracción de Aristóteles complementado fundamentalmente con la lectura del De Anima al momento de comprender las concepciones internas como especies inteligibles. Llama la atención que Ockham, en su última etapa filosófica, no se detiene en ulteriores explicaciones en el campo psicológico y al parecer muestra con toda contundencia su exclusiva opción por el análisis del lenguaje al momento de esclarecer el problema del concepto. Su opción por la vía lógica obedece a la pretensión del autor de ejecutar una lectura más acorde al pensamiento general de Aristóteles, una lectura que irrumpe frente al mundo escolástico de las esencias que, para él, oculta como un manto los hechos, esto es, el trato con los singulares que configuran nuestro mundo. A partir de ese momento, la relación pensamiento-lenguaje queda establecida y marca no sólo la posición nominalista frente al conocimiento sino también una incipiente perspectiva lógica de enfrentar los problemas asociados a la filosofía y con ello una nueva forma de reconocer el estatuto de nuestros conceptos.

\footnotetext{
36 En palabras de Ockham: "Qualis autem sit ista passio, an scilicet sit aliqua res extra animan, vel aliquid realiter exsistens in anima, vel aliquod ens fictum exsistens tantum in anima obiective, non pertinet ad logicum sed ad metaphysicum considerare" (1978: 349).
} 


\section{CONCLUSIONES}

Para Ockham la consideración de un cosmos contingente conlleva la posibilidad del cambio de los singulares como de los hechos que articulan el mundo, posición que impone a su vez la de los conceptos formulados en enunciados que develan el despliegue de nuestra dinámica experiencia humana, de este modo, para el pensador inglés se erige un nuevo criterio de objetividad en función de la persistente observación de los diversos individuos que configuran los hechos. Se inicia, por tanto, una nueva era donde la explicación arquetípica del cosmos comienza a ser desplazada por una paulatina "descripción" de la realidad cuestión representada, principalmente, por un giro semántico hacia la comprensión de nuestros conceptos y, por tanto, del detenido examen de la denotación de nuestros términos. En consecuencia, para el Venerabilis Inceptor los conceptos en cuanto signos naturales de las cosas hacen referencia a los singulares y sus mutuas relaciones. En este marco, los conceptos como un espejo hacen referencia a los singulares que enlazan el mundo, análisis elaborado desde un punto de vista semántico.

El hombre y sus juicios, por consiguiente, deben atenerse a los hechos, pero más aún, deben remitirse en forma permanente a singulares que contienen la posibilidad del cambiar. En este sentido, la mirada de Ockham del cosmos es un preludio del amanecer de un nuevo horizonte intelectual, diverso a lo ante vislumbrado por la búsqueda de principios inmutables que podrían explicar la naturaleza esencial de las cosas. En este nuevo horizonte las puertas que abrirá el conocimiento intuitivo de los singulares ya no podrán ser cerradas, los individuales aparecerán con toda su importancia revestidos ahora por la contingencia. De este modo, la renuncia a la prioridad del conocimiento abstracto e inmutable otorga nuevas posibilidades a la lógica de Ockham que se sumerge en un mundo en cambio. Podemos comprender, por tanto, que el verdadero motivo del conocimiento intuitivo es la aceptación, en este caso, de constelaciones de objetos que libremente se comportan provocando diversos desenlaces entre los cuales se devela la contingencia misma de la creación, manifestada por el gobierno de un Dios Omnipotente que puede conducir su obra a las más diversas posibilidades que la lógica le otorgue.

En definitiva, la lectura nominalista del concepto y su rol en la conformación del conocimiento irrumpirá en la manera de entender la Filosofía. El análisis semántico del concepto de Ockham posibilitará un auge de la lógica medieval, lo cual impone un modo distinto de acceder al conocimiento mediante el análisis de diversos discursos que permitan la comprensión de los particulares a través del examen de la referencia de 
nuestros conceptos. Por consiguiente, el acercamiento al examen del pensamiento desde una lectura lógica del mundo conllevará importantes consideraciones filosóficas en los períodos posteriores, lo que constituirá un avance en el desarrollo del conocimiento, esta vez con principal protagonismo del detenido análisis del lenguaje.

\section{REFERENCIAS}

Afnan, S. (1965). Elpensamiento de Avicena. (V. Yamuni, Trad.). México: FCE.

Alberti Magni (1890). Opera Omnia (Vol. 1, Logicae prima). Paris: Ludovicum Vives.

Aquino, T. de (1986). Exposición del De Trinitate de Boecio. (A. García y J. A. Fernández, Trads.). Pamplona: EUNSA.

Aquino, T. de (1990). Comentarios al Peri Hermeneias. (M. Skarica, Trad.). Valparaíso: Ed. Cerro Alegre.

Aquino, T. de (1999). Cuestiones disputadas sobre el alma. (E. Telles, Trad.). Pamplona: EUNSA.

Aquino, T. de (2005). Comentario a las Sentencias II/1. (J. Cruz, Trad.). Pamplona: EUNSA.

Aquino, T. de (2009). Suma de Teología. (D. Byrne, Trad.). Madrid: BAC.

Aristóteles (2007). Metafísica. (T. Calvo, Trad.). Madrid: Gredos.

Avicena (2006). Cuestiones divinas (C. Segovia, Trad.). Madrid: Biblioteca Nueva.

Avicena (2009). Avicena esencial (J. Lomba, Ed.). Madrid: Ed. Montesinos.

Brennan, R. (1960). Psicología tomista. Madrid: Aguilar.

Cruz, M. (1963). La filosofía árabe. Madrid: Revista de occidente.

De Andrés, T. (1969). El nominalismo de Guillermo de Ockham como filosofía del lenguaje. Madrid: Gredos.

Elders, L. (2009). Conversaciones filosóficas con Santo Tomás de Aquino. Mendoza: Ediciones del Verbo Encarnado San Rafael.

Fernández, C. (1980). Filósofos medievales (Selección de textos). Madrid: BAC.

Forment, E. (2009). Metafísica. Madrid: Ediciones Palabra.

Gilson, E. (1976). La filosofía en la Edad Media. Madrid: Gredos.

Gilson, E. (2005). El ser y los filósofos. (S. Fernández, Trad.). Pamplona: EUNSA

Le Goff, J. (2008). Los intelectuales en la Edad Media. (A. Bixio, Trad.). Barcelona: Gedisa.

Manser, P. M. G. (1947). La esencia del Tomismo. (V. García Yebra, Trad.). Madrid: Gredos.

Martínez, J.-P. (2018). Ockham y Wittgenstein. Acerca de los alcances y límites de la relación pensamiento-lenguaje. Revista de Humanidades de Valparaíso, (12), 69-93.

Ockham, G. (1967). Scriptum in Librum Primum Sententiarum, Ordinatio, Prologus et Distintio Prima (Opera Theologica Vol. I). New York: The Franciscan Institute. 
Ockham, G. (1970). Scriptum in Librum Primum Sententiarum, Ordinatio, Prologus et Distintiones Secunda et Tertia (Opera Theologica Vol. II). New York: The Franciscan Institute.

Ockham, G. (1974). Summa Logica, (Opera Philosophica Vol. I). New York: The Franciscan Institute.

Ockham, G. (1978). Expositionis in Libros Artis Logicae Prooemium et Expositio in Librum Perihermeneias Aristotelis, (Opera Philosophica Vol. II). New York: The Franciscan Institute.

Panaccio, C. (2004). Ockham on Concepts. Quebec: Ashgate.

Parain, B. (2004). Historia de la Filosofía (Vol. 3; P. Muñoz, J. M. Alvarez y P. López, Trads.). México: Siglo veintiuno editores.

Spade, P. V. (2007). Thougths, words and things: An introduction to late mediaeval logic and semantics. Bloomington: Indiana University.

Spruit, L. (1994). From perception to Knowledge. New York: E.J. Brill.

Torrell, J.-P. (2002). Iniciación a Tomás de Aquino: su persona y su obra. Pamplona: EUNSA. 